\title{
UPAYA MENINGKATKAN MINAT BELAJAR MATEMATIKA DENGAN PENDEKATAN OPEN-ENDED
}

\author{
Weni Gurita Aedi \\ UNPAM, Tangerang Selatan, Indonesia \\ E-mail:wenigurita@gmail.com
}

\begin{abstract}
Abstrak. Minat belajar merupakan modal awal siswa untuk belajar. Minat belajar merupakan dorongan dari dalam diri siswa secara psikis untuk mempelajari sesuatu dengan kesadaran, ketenangan dan kedisiplinan, sehingga siswa dapat secara aktif dan senang untuk melakukannya. Namun faktanya minat belajar matematika siswa masih perlu ditingkatkan. Sehingga perlu dilakukankan upaya untuk menciptakan suatu pembelajaran yang aktif, kreatif dan inovatif yang dapat meningkatkan minat belajar matematika siswa. Salah satu yang dilakukan yaitu dengan menerapkan pendekatan open-ended. Penelitian ini merupakan penelitian tindakan kelas (PTK) dengan menerapkan pendekatan open-ended untuk meningkatkan minat belajar matematika. PTK dilakukan dalam dua siklus. Tiap siklus terdiri dari kegiatan perencanaan, tindakan, pegamatan, dan refleksi. Hasil penelitian menunjukkan bahwa pendekatan open-ended dapat meningkatkan minat belajar matematika matematika siswa. Setelah dilakukan upaya-upaya perbaikan, pada penerapan pendekatan open-ended dalam pembelajaran matematika dari siklus I ke siklus II dapat meningkatkan minat belajar matematika siswa
\end{abstract}

Keywords: minat belajar, open-ended, matematika, PTK

\section{PENDAHULUAN}

Matematika merupakan ilmu yang ada di setiap aspek kehidupan. Permendiknas Nomor 22 Tahun 2006 tentang Standar Isi Mata Pelajaran Matematika untuk jenjang pendidikan dasar dan menengah menyatakan bahwa salah satu tujuan mata pelajaran matematika di sekolah yaitu "memiliki sikap menghargai kegunaan matematika dalam kehidupan, yaitu memiliki rasa ingin tahu, perhatian, dan minat dalam mempelajari matematika, serta sikap ulet dan percaya diri dalam pemecahan masalah". Hal ini dapat menunjukkan bahwa peningkatan minat siswa merupakan salah satu tujuan pembelajaran matematika di sekolah. Untuk itu, guru harus mampu menciptakan pembelajaran yang dapat meningkatkan minat siswa dalam pembelajaran matematika.

Minat belajar merupakan modal awal siswa untuk memulai belajar. Menurut Collate \& Chiappetta (1974: 74) minat sebagai rasa keingintahuan atau daya tarik pada suatu pemikiran atau kejadian yang melibatkan perhatian. Lebih lanjut, minat belajar merupakan dorongan dalam diri siswa secara psikis dalam mempelajari sesuatu dengan penuh kesadaran, ketenangan dan kedisiplinan, sehingga siswa dapat secara aktif dan senang untuk melakukannya (Guilford,1969 : 206). Dalam pembelajaran matematika, guru dan siswa dapat saling mengembangkan minat belajar yaitu dengan cara guru bertindak sebagai fasilitator yang dapat mendukung proses pembelajaran sehingga siswa akan memiliki semangat, dorongan, dan sikap aktif dalam proses pembelajaran.

Menurut Elliot, et al (2000 : 349) hal yang bisa dilakukan oleh guru untuk memfasilitasi dalam pengembangan minat yaitu mengundang siswa untuk berpartisipasi pada tugas penuh arti dengan menghubungkan ke dunia luar kelas, menyediakan aktivitas yang memerlukan keterlibatan siswa dan menyediakan mereka tantangan yang disesuaikan dengan perkembangan mental, mengijinkan siswa untuk mempunyai satu peran dalam mengevaluasi pekerjaan mereka sendiri dan monitoring kemajuannya, memudahkan integrasi dan penggunaan pengetahuan, serta belajar bekerjasama dengan siswa lain. Oleh karena itu, minat belajar matematika diharapkan muncul secara maksimal, baik dengan munculnya perasaan senang, perhatian maupun adanya ketertarikan dalam belajar matematika.

Namun berdasarkan pra penelitian yang dilakukan di SMP N 1 Pleret Bantul dengan membagikan angket minat belajar matematika kepada siswa Kelas VII-G, diperoleh kondisi awal minat belajar matematika seperti pada Tabel 1 berikut. 


\section{- - - Jurnal Pendidikan Matematika Indonesia \\ Volum 3 Nomor 2 bulan September 2018 Page 41 - 46 \\ p-ISSN: 2477-5967 e-ISSN: 2477-8443}

TABEL 1.

KONDISI AWAL MINAT BELAJAR MATEMATIKA SISWA KELAS VII-G

\begin{tabular}{ll}
\hline Kriteria & Minat siswa \\
\hline Sangat tinggi & $6,67 \%$ \\
Tinggi & $30 \%$ \\
Sedang & $60 \%$ \\
Rendah & $3,33 \%$ \\
Sangat rendah & $0 \%$ \\
Rata-rata & 82,33 (Sedang) \\
\hline
\end{tabular}

Berdasarkan data pada Tabel 1 tersebut, sebagian besar minat belajar matematika pada siswa kelas VII-G SMP N 1 Pleret Bantul masih dalam kategori sedang, sehingga perlu adanya upaya untuk meningkatkan minat belajar matematika agar meningkat kedalam kategori tinggi.

Selain itu, pada hasil observasi pembelajaran matematika yang berlangsung di kelas VII-G SMP Negeri 1 Pleret Bantul, terlihat bahwa masih terdapat beberapa siswa yang kurang aktif ketika pelajaran matematika, siswa hanya mendengarkan penjelasan guru saja, siswa terlihat ramai dan berbicara dengan temannya ketika pelajaran matematika berlangsung. Serta siswa malu bertanya kepada guru apabila mengalami kesulitan. Hal tersebut juga dapat menjadi indikasi bahwa minat belajar matematika siswa kelas VII-G SMP Negeri 1 Pleret Bantul masih perlu ditingkatkan. Oleh karena itu, guru diharapkan dapat menciptakan suatu pembelajaran yang aktif, kreatif dan inovatif yang dapat meningkatkan minat belajar matematika.

Suatu tantangan bagi guru untuk menciptakan pembelajaran matematika yang aktif, kreatif dan inovatif yang dapat meningkatkan minat belajar matematika siswa. Kegiatan yang dilakukan dapat dimulai dari perencanaan belajar yang dilakukan oleh guru. Skemp (1971: 114) menyatakan bahwa guru perlu untuk menganalisis konsep materi dan perencanaan pembelajaran secara hati-hati sebelum melaksanakan pembelajaran di kelas. Guru merencanakan pengalaman matematis yang berharga, berinteraksi dengan siswa ketika mereka belajar, dan memonitoring kemajuan siswa (Kennedy, Tipps, \& Johnson, 2008: 58). Antara guru dan siswa harus ada saling keterkaitan satu sama lain, sehingga perlu adanya hubungan dan kerjasama antara keduanya agar dapat dicapai tujuan yang diharapkan.

Secara umum jika dilihat dari karakteristik siswa itu sendiri, siswa SMP kelas VII berada pada masa puber dimana peralihan dari masa anak-anak ke masa remaja yang membutuhkan sesuatu yang dapat menarik minat, perhatian, rasa keingintahuan, membangkitkan semangat, ataupun sesuatu yang berbeda dari yang selama ini didapatkan ketika pelajaran matematika. Proses pembelajaran matematika akan lebih menyenangkan, tidak membosankan dan mudah untuk dipahami siswa jika menggunakan metode pembelajaran yang dapat menumbuhkan minat belajar matematika siswa. Sehingga dalam proses pembelajaran sangat diperlukan suatu pendekatan untuk meningkatkan minat belajar matematika dengan melibatkan siswa secara aktif dalam proses pembelajaran. Guru dapat memilih berbagai pendekatan dengan mempertimbangkan perkembangan kognitif, afektif, psikomotorik, waktu yang tersedia serta sarana prasarana yang ada. Salah satu pendekatan tersebut yaitu pendekatan open-ended.

Pembelajaran dengan pendekatan open-ended merupakan pembelajaran yang lebih menekankan pada upaya siswa untuk sampai ada jawaban daripada kebenaran jawaban semata. Shimada (1997: 1) mengemukakan pendekatan open-ended yaitu suatu pendekatan pembelajaran yang menyajikan permasalahan yang memiliki metode atau penyelesaian yang benar lebih dari satu, sehingga memberi kesempatan kepada siswa untuk memperoleh pengetahuan menemukan, mengenali dan memecahkan masalah dengan beberapa teknik. Siswa diharapkan pada suatu masalah memiliki jawaban lebih dari satu dan guru tidak membatasi metode penyelesaian yang digunakaan oleh siswa. Bahkan sebaliknya siswa diberi keleluasaan mencari dan menggunakan berbagai cara atau metode dalam memecahkan masalah. Selain itu, pendekatan open-ended menyediakan pengalaman bagi siswa untuk menemukan sesuatu yang baru.

Menurut Takahashi (2008: 2), bila pendekatan openended diberikan pada siswa di sekolah, setidaknya ada lima keuntungan yang dapat diharapkan. Pertama, siswa berpartisipasi lebih aktif pada pembelajaran dan dapat mengekspresikan ide mereka dengan lebih sering. Jadi para siswa tak hanya pasif menirukan cara yang hanya dicontohkan gurunya. Kedua, siswa mempunyai kesempatan yang lebih untuk secara komprehensif menggunakan pengetahuan dan ketrampilan. Jadi mereka akan terlibat dalam menggunakan potensi pengetahuan dan ketrampilan yang sudah dimiliki sebelumnya. Ketiga, siswa yang berkemampuan rendah akan dapat memndang masalah dan mampu menyelesaikan dengan cara mereka sendiri. Jadi kreativitas siswa akan dapat terungkapkan. Keempat, siswa akan termotivasi secara intrinsik untuk dapat memberikan bukti. Kelima, siswa yang kaya pengalaman akan senang menemukan serta menerima persetujuan dari siswa lain terhadap ide-ide mereka.

\section{KAJIAN LITERATUR}

Beberapa penelitian yang relevan dengan penelitian ini, antara lain: Penelitian Harta dan Rahmawati (2014) menyatakan bahwa dengan menggunakan pendekatan openended, dapat meningkatkan hasil belajar kognitif maupun afektif. Dalam penelitian ini, jika ditinjau dari hasil belajar afektif siswa yaitu sikap dan minat belajar matematika siswa maka pendekatan open-ended dinyatakan efektif. Kerelevansian penelitian ini adalah pada penggunaan openended dalam proses pembelajaran yaitu untuk meningkatkan minat belajar matematika siswa. Bila Idris Harta dan Yeni Rahmawati menerapkan open-ended pada siswa untuk meningkatkan prestasi belajar dan kemampuan berpikir kreatif serta hasil belajar afektif (sikap dan minat siswa terhadap matematika), maka dalam penelitian ini menggunakan open-ended pada pembelajaran matematika siswa SMP kelas VII untuk meningkatkan minat belajar matematika siswa. 
Penelitian Al-Absi (2012) menyatakan bahwa melalui pendekatan open-ended dapat memperkuat pengetahuan siswa karena memaksa siswa untuk memikirkan masalah matematika menggunakan segala kemampuan dimiliki untuk mencapai alternatif jawaban yang benar jika ditemukan, dan terungkap dalam penelitian ini melalui peningkatan prestasi belajar matematika dan rasa percaya diri siswa. Kerelevansian penelitian ini adalah pada penerapan openended dalam proses pembelajaran matematika. Bila Al-Absi menerapkan open-ended untuk meningkatkan prestasi belajar matematika dan kepercayaan diri siswa, maka dalam penelitian ini menggunakan pendekatan open-ended pada pembelajaran SMP kelas VII untuk meningkatkan minat belajar matematika siswa.

Penelitian Kwon, Park dan Hyun (2006) menyatakan bahwa dengan menggunakan pendekatan open-ended, siswa dapat meningkatkan kemampuan berpikir divergennya. Kerelevansian penelitian ini adalah pada penggunaan openended dalam proses pembelajaran matematika. Bila Oh Nam Kwon, Jung Sook Park dan Jee Hyun Park. menerapkan open-ended pada kelas VII untuk meningkatkan kemampuan berpikir divergen siswa, maka penelitian menggunakan pendekatan open-ended pada siswa SMP kelas VII untuk meningkatkan minat belajar matematika siswa.

Penelitian Melianingsih (2014) mengemukakan pendekatan open-ended pada pembelajaran matematika dinyatakan efektif ditinjau dari pencapaian kemampuan penalaran, pemecahan masalah, dan komunikasi matematis siswa kelas VIII SMP. Kerelevansian penelitian ini adalah pada penerapan open-ended dalam proses pembelajaran matematika. Bila Nuning Melianingsih menerapkan pendekatan open-ended untuk pencapaian kemampuan penalaran, pemecahan masalah, dan komunikasi matematis siswa, maka pada penelitian ini pendekatan open-ended pada pembelajaran matematika SMP kelas VII untuk meningkatkan minat belajar matematika siswa.

\section{METODE PENELITIAN}

Jenis penelitian ini adalah penelitian tindakan kelas (PTK) atau classroom action research yang dilakukan secara kolaboratif. Kolaboratif artinya berkolaborasi dengan guru matematika di kelas VII-G SMP N 1 Pleret Bantul. Penelitian tindakan kelas ini menggunakan desain yang dikembangkan oleh Kemmis \& Mc Taggart yang terdiri dari empat tahap yait planning (perencanaan), action (pelaksanaan), observation (pengamatan), dan reflection (refleksi) (Kemmis \& Taggart, 1991: 32. Komponen pelaksanaan dan pengamatan sebagai satu kesatuan. Hasil dari pengamatan ini dijadikan dasar langkah berikutnya, yaitu refleksi. Dari refleksi disusun sebuah modifikasi yang diaktualisasikan dalam bentuk rangkaian tindakan dan pengamatan lagi begitu seterusnya, sesuai dengan Gambar 1 berikut.

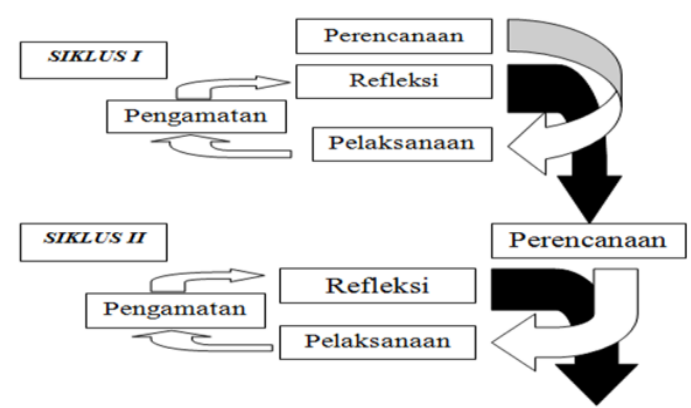

Gambar 1. Alur Penelitian Tindakan Kelas

Subjek penelitian ini adalah siswa kelas VII-G SMP N 1 Pleret Bantul tahun ajaran 2015/2016 berjumlah 30 siswa, terdiri dari 20 siswa perempuan dan 10 siswa laki-laki. Masing-masing siswa memiliki karakteristik berbeda satu sama lain. Mereka dari latar belakang berbeda, memiliki kemampuan berbeda, kemudian disatukan dalam satu kelas untuk saling belajar.

Data dikumpulkan melalui beberapa teknik antara lain: 1) Observasi,dilakukan oleh guru dengan cara melakukan pengamatan kemudian memberikan tanda check mengenai keterlaksanaan pembelajaran matematika di kelas yang meliputi aktivitas guru dan aktivitas siswa. 2) Tes dilakukan untuk mengetahui sejauh mana prestasi belajar siswa. 3) Angket, digunakan untuk mengetahui sejauh mana minat belajar matematika siswa.

Data hasil penelitian dianalisis secara deskriptif untuk setiap siklus. Teknik analisis data digunakan untuk mengetahui pelaksanaan pembelajaran matematika menggunakan pendekatan open-ended. Data yang akan dianalisis adalah data yang diperoleh selama penelitian berlangsung, berupa data angket minat belajar, data tes prestasi belajar dan data observasi keterlaksanaan pembelajaran, pada masing-masing siklus.

Data angket minat belajar dianalisis dengan mengubah skor rata-rata dari setiap penilaian menjadi nilai kualitatif berdasarkan kriteria penilaian skala lima (Azwar, 2010).

Tabel 2.

KONVERSI SKOR MINAT BELAJAR

\begin{tabular}{ll}
\hline Interval Skor & Kriteria \\
\hline $\bar{X}>\overline{\mathrm{X}} \mathrm{i}+1,5 \mathrm{SBi}$ & Sangat Tinggi \\
$\overline{\mathrm{X}} \mathrm{i}+0,5 \mathrm{SBi}<X \leq \overline{\mathrm{X}} \mathrm{i}+1,5 \mathrm{SBi}$ & Tinggi \\
$\overline{\overline{\mathrm{X}}}-0,5 \mathrm{SBi}<\bar{X} \leq \overline{\mathrm{X}} \mathrm{i}+0,5 \mathrm{SBi}$ & Sedang \\
$\overline{\mathrm{X}} \mathrm{i}-1,5 \mathrm{SBi}<X \leq \overline{\mathrm{X}} \mathrm{i}-0,5 \mathrm{SBi}$ & Rendah \\
$\bar{X} \leq \overline{\mathrm{X}} \mathrm{i}-1,5 \mathrm{SBi}$ & Sangat Rendah \\
\hline
\end{tabular}

Dimana :

$\overline{\mathbf{x}} \mathbf{i}=1 / 2$ (skor maksimal ideal + skor minimum ideal)

$\mathrm{SBi}=1 / 6$ (skor maksimal ideal - skor minimum ideal $)$

Data tes prestasi belajar dianalisis untuk menyimpulkan presentase siswa yang tuntas. Siswa dinyatakan tuntas apabila memperoleh nilai minimal 75 , sesuai dengan nilai KKM yang ditetapkan di SMP N 1 Pleret Bantul yaitu 75. Indikator keberhasilan dalam penelitian tindakan kelas (PTK) ini adalah: 1) peningkatan rata-rata skor minat belajar 


\section{- - - - Jurnal Pendidikan Matematika Indonesia \\ Volum 3 Nomor 2 bulan September 2018 Page 41 - 46 \\ p-ISSN: 2477-5967 e-ISSN: 2477-8443}

matematika siswa kelas VII-G SMP N 1 Pleret Bantul dari kondisi awal minat belajar matematika siswa dengan ratarata 82,33 kategori sedang meningkat menjadi kategori tinggi. 2) peningkatan presentase siswa yang mencapai ketuntasan dalam tes prestasi belajar yaitu sebanyak $75 \%$ siswa kelas VII-G SMP N 1 Pleret Bantul mencapai target ketuntasan. Siswa dikatakan tuntas apabila mendapatkan nilai minimal 75 dalam tes prestasi belajar. 3) Keterlaksanaan pembelajaran matematika dengan Pendekatan open-ended yang di peroleh melalui lembar observasi minimal mencapai $85 \%$.

\section{HASIL DAN PEMBAHASAN}

Penelitian Tindakan Kelas (PTK) ini dilaksanakan di kelas VII G SMP N 1 Pleret Bantul sebanyak 2 siklus. Siklus I terdiri dari 3 kali pertemuan dengan materi aritmetika sosial, sedangkan siklus II terdiri dari 2 kali pertemuan dengan materi perbandingan. Setiap awal siklus, siswa mengerjakan soal pretest untuk mengetahui kemampuan awal siswa. Pelaksanaan pembelajaran, menggunakan LKS yang telah disiapkan dan diberikan kepada setiap siswa. Siswa berdiskusi dalam kelompok-kelompok kecil yang terdiri dari 4 orang siswa. Pada akhir setiap siklus siswa diberi posttest yang bertujuan mengukur prestasi belajar siswa dan melihat ketercapaian target penelitian.

Proses pembelajaran matematika pada siklus I belum berjalan dengan maksimal karena siswa siswa belum terbiasa pembelajaran dengan pendekatan open-ended. Pengkondisian siswa masih belum maksimal, terdapat beberapa siswa sering gaduh dan masih kurang fokus dalam mengikuti pembelajaran. Pada kegiatan diskusi masih ada siswa yang tidak aktif dikelompoknya sehingga senantiasa diingatkan bahwa dalam berkelompok setiap siswa hendaknya tidak egois. Apabila ada anggota kelompoknya yang kurang paham maka anggota kelompok yang lebih paham wajib menjelaskan, karena pembagian setiap kelompok beranggotakan siswa yang bekemampuan tinggi, sedang dan rendah. Setiap siswa harus saling tolong menolong agar diskusi berjalan lancar. Ada pula kelompok siswa yang mengalami kesulitan dalam disksui sehingga butuh bimbingan ekstra. Namun pada siklus II, siswa sudah mulai terbiasa dengan pembelajaran menggunakan pendekatan open-endeed.

Secara keseluruhan penerapan pembelajaran matematika dengan pendekatan open-ended telah berjalan lancar. Target penelitian terkait keterlaksanaan proses pembelajaran telah tercapai, yaitu keterlaksanaan pembelajaran telah mencapai lebih dari $85 \%$ yang ditunjukkan Gambar 2 berikut.

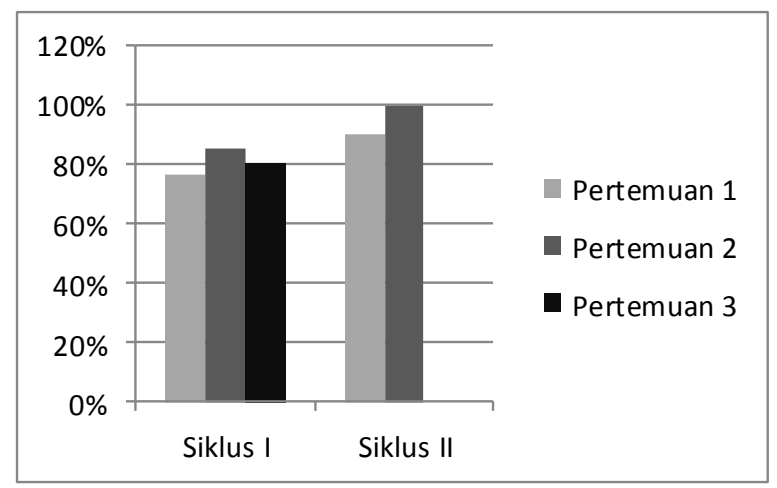

Gambar 2. Keterlaksanaan Proses Pembelajaran Siklus I dan Siklus II
Minat belajar matematika siswa secara umum mengalami peningkatan dan dapat mencapai indikator keberhasilan yang telah ditetapkan setelah dilakukan perbaikan pada penerapan pendekatan open-ended dalam pembelajaran matematika dari siklus I ke siklus II. Rata-rata hasil angket minat belajar matematika siswa meningkat dari 86,13 (tinggi) pada siklus I menjadi 88,4 (tinggi) pada siklus II. Persentase siswa yang mencapai minat belajar matematika dalam kategori tinggi pun mengalami peningkatan dari $36,67 \%$ menjadi $46,67 \%$. Hal ini menunjukan setelah dilakukan upaya-upaya perbaikan pada penerapan pendekatan open-ended dalam prose pembelajaran matematika dapat meningkatkan minat belajar matematika siswa yang ditunjukkan Gambar 3 berikut.

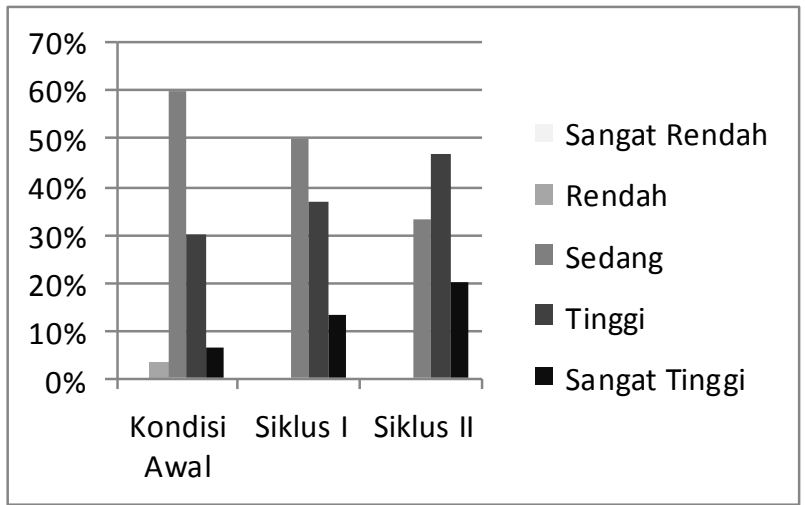

Gambar 3. Peningkatan Minat Belajar Matematika Siswa

Berdasarkan hasil tes dari siklus I ke siklus II secara umum prestasi belajar matematika siswa mengalami peningkatan dan dapat mencapai indikator keberhasilan yang telah ditetapkan setelah dilakukan perbaikan pada penerapan pendekatan open-ended dalam pembelajaran matematika. Rata-rata hasil tes siswa meningkat dari 73,47 menjadi 80,89. Persentase siswa yang mencapai KKM pun mengalami peningkatan dari $66,67 \%$ menjadi $76,67 \%$. Hal ini mengindikasikan bahwa dengan menggunakan pendekatan open-ended dalam pembelajaran matematika ternyata juga dapat meningkatkan prestasi belajar matematika siswa yang ditunjukkan Gambar 4 berikut.

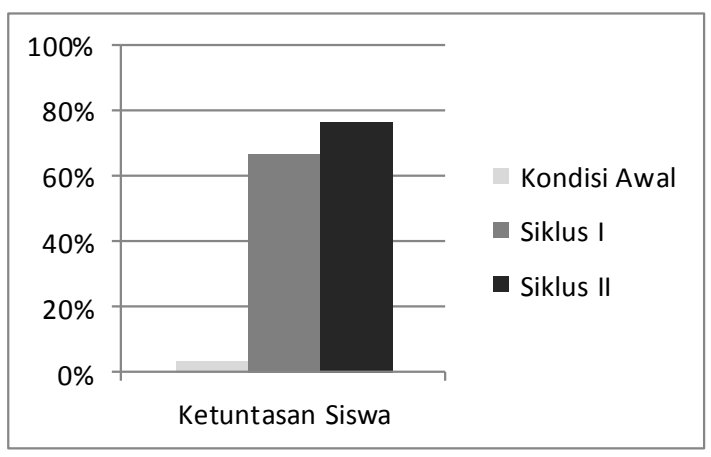

Gambar 4. Persentase Ketuntasan Belajar Siswa

Hasil penelitian ini menguatkan penelitian terdahulu tentang pembelajaran menggunakan pendekatan open-ended, khususnya pembelajaran matematika. Penelitian terdahulu mengenai pendekatan open-ended yang telah dilakukan oleh Indris Harta dan Yeni Rahmawati ES (2014) menyatakan 
bahwa prestasi belajar matematika siswa dengan pendekatan open-ended dan minat belajar matematika lebih tinggi daripada prestasi belajar siswa menggunakan model pembelajaran ekspositori.

\section{KESIMPULAN}

Berdasarkan hasil observasi terhadap keterlaksanaan proses pembelajaran matematika degan pendekatan openended, angket minat belajar matematika dan tes prestasi belajar matematika siswa kelas VII-G SMP N 1 Pleret Bantul dapat ditarik kesimpulan sebagai berikut:

1. Pada akhir siklus I keterlaksanaan proses pembelajaran matematika menggunakan pendekatan open-ended materi aritmatika sosial mencapai $80,95 \%$. Hasil ini telah meningkat pada siklus II yaitu materi perbandingan yang mencapai $95.24 \%$ (lebih dari target penelitian).

2. Kriteria Ketuntasan Minimal (KKM) dengan nilai ratarata 73,47 pada tes prestasi belajar akhir siklus I, materi aritmatika sosial,. Hasil ini juga meningkat pada siklus II, yaitu pada tes prestasi belajar materi perbandingan sebanyak $76,67 \%$ siswa telah mencapai KKM dengan nilai rata-rata 80,89 .

3. Minat belajar matematika siswa berada pada kategori tinggi dengan rata-rata 86,13 pada akhir siklus I. Hasil ini meningkat pada akhir siklus II dengan rata-rata 88,4.

\section{DAFTAR PUSTAKA}

Anderson, L. W .(1981). Assessing affective characteristics in the schools. Boston, MA: Allyn and Bacon.

Azwar, S. (1996). Tes prestasi fungsi pengembangan pengukuran prestasi belajar. Yogyakarta: Pustaka Belajar.

Bell, F.H. (1978). Teaching and learning mathematics (in secondary school). Dubuque, IA: Wm. C. Brown Company Publishers.

Bell-Gredler \& Margaret. (1986). Learning and instruction, theory into practice. New York: Collier Macmillan Canada

Bruner, Jerome S. (1971). Toward a Theory of Instruction. Massachusetts: The Belknap Press.

Chambers, P. (2008). Teaching mathematics developing as a reflective secondary teacher. London: SAGE Publications.

Collette, A. T., \& Chiapetta, E. L. (1994). Science instruction in the middle and secondary schools $\left(3^{\text {rd }}\right.$ ed). New York: Maxwell Macmillan, Inc.

Depdiknas. (2006). Peraturan Menteri Pendidikan Nasional Nomor 22 Tahun 2006. Tentang Standar Isi

Djaali. (2008). Psikologi Pendidikan. Jakarta: Bumi Aksara.

Elliott, S.N., Kratochwill, T.R, Cook, J. L., \& Travers, J.F. (2000). Educational psychology: Effective teaching, effective learning ( $3^{\text {rd }}$ ed). Boston: McGraw-Hill

Evans, B. (2007). Student attitudes, conceptions, and achievement in introductory undergraduate college statistics. The mathematics educator 2007, Vol. 17,
No. 2, 24-30. Diambil dari http://math.coe.uga.edu/tme/issues/v17n2/v17n2_Eva ns.pdf

Gable, R.K. (1986). Instrument development in the effective domain. Boston: Kliewe Nijhoff Publishing.

Gareis, C. R \& Grant, L. W. (2008). Teacher-made assesments: how to connect, curriculum, instruction, and student learning. New York: Eye On Education.

Gronlund, N.E. (1982). Constructing achievement test. Englewood Cliffs. New Jersey: Prentice Hall.

Hashimoto, Y. (1997). An Example of lesson development. Dalam J. P. Becker dan S. Shimada (eds). The Open-Ended Approach: A New Proposal for Teaching Mathematics. Reston, VA: NCTM.

Hiroshima, M. (1997). Review of linear functions. Dalam J. P. Becker dan S. Shimada (eds). The Open-Ended Approach: A New Proposal for Teaching Mathematics. Reston, VA: NCTM.

Ishiyama, H. (1997). Right triangle and the "connecting middle points" theorem. Dalam J. P. Becker dan S. Shimada (eds) The Open-Ended Approach: A New Proposal for Teaching Mathematics. Reston, VA: NCTM

Idris Harta \& Yeni Rahmawati ES. (2014). Keefektifan Penedektan Open-Ended dan CTL Ditinjau Dari Hasil Belajar Kognitif Dan Afektif. Jurnal Riset Pendidikan Matematika UNY, Volume 1 Nomor 1 Mei 2014

Jihad, A. (2008). Pengembangan kurikulum matematika (tinjauan teoritis dan historis. Yogyakarta: Multi Pressindo

Kemmis, S. \& Taggart, R. (1991). The action research planner. Victoria University Press.

Joyce, B., \& Weil, M. (1996). Models of teaching. Boston: Allyn and Bacon

J.P Guilford. 1969. Personallity. New York: MC.Graw Hill Book Company.

Kennedy, M.L., Tipps, S,. \& Johnson,A. (2008). Guiding children's learning of mathematics. New York, NY: Thomson Higher Education.

Lianghuo Fan \& Yan Zhu. (2008). Using performance assesment in secondary school mathematics: an empirical study in a Singapore classroom. Journal of Mathematics Education, Vol. 1, No. 1, pp. 132135.

http://educationforatoz.com/images/11FanUsingPer formanceAssesmentproofreadingdone-4. pdf.

Masingila, J.O. (2002). Examining students' perceptions of their everyday mathematics practice. Dalam Brenner, M.E. \& Moschkovich, J.N.(Eds.), Everyday and academic mathematics in the classroom(pp. 30-39). Reston, VA: NCTM.

Mcintosh, R \& Jarret, D. (2000). Teaching mathematical problem solving. Boston, MA: Mathematics and science Education Center.

Mohammad Al-Absi. (2012). The Effect of Open-ended Tasks -as an assessment tool- on Fourth Graders' Mathematics Achievement, and Assessing 
Students' Perspectives about it. Jordan Journal of Educational Sciences Vol. 9, No. 3, pp 345-351

NCTM. (2000). Principles and standards for school mathematics.Reston, VA: NCTM.

Nitko., A. J, \& Brookhart, S. M. (2007). Educational assesment of students. Boston, MA: Pearson (Merill Prentice Hall).

Nohda, N. (2000). A study of "open-ended approach mathod in school mathematics teaching-focusing on mathematical problem solving activities. Paper disajikan dalam the ninth International Congress on Mathematics Education (ICME): Mathematics Education in Pre and Primary School, di Makuhari, Jepang

Nuning Melianingsih. (2014). Kefektifan pendekatan openended dan problem solving pada pembelajaran matematika di SMP N 1 Pandak Bantul ditinjau dari pencapaian kemampuan penalaran, pemecaham masalah dan komunikasi matematis. Tesis. Universitas Negeri Yogyakarta

Oh Nam Kwon, Jung Sook Park, Jee Hyun Park .(2006). Cultivating Divergent Thinking in Mathematics through an Open-Ended Approach. Education Research Institute, Vol. 7, No. 1, 51-61.

Pritchard, A. \& Woollard, J. (2010). Psychology for the classroom: contructivism and social learning. New York: Routledge
Rathus, S. A. (2014). Childhood and adolescence voyages in development (5th ed). Belmont: Wadsworth Cengage Learning.

Sawada, T. (1997). Developing lesson plans. Dalam J. P. Becker dan S. Shimada (ed) The Open-Ended Approach: A New Proposal for Teaching Mathematics. Reston, VA: NCTM.

Sax, G. (1980). Principles of educational and psychological measurement and evaluation $\left(2^{\text {nd }} e d\right)$. California: Wadsworth Publishing Company.

Shimada, S., \& Becker, J. (1997). The Significance of an open-ended approach. Dalam J. P. Becker dan S. Shimada (ed) The Open-Ended Approach: A New Proposal for Teaching Mathematics. Reston, VA: NCTM

Skemp, R. (1971). The psychology of learning mathematics. Bungay, Suffolk:Richard Clay (The Chaucer Press) Ltd.

Sutherland, R. (2007). Teaching for learning mathematics. New York, NY: Open University Press.

Takahashi, A. (2006). Communication as Process for Students to Learn Mathematical. [online]. Tersedia: http://www.criced.tsukuba.ac.jp/math/apec/apec200 8/papers/PDF/14.Akihiko_Takahashi_USA.pdf. 